\title{
Hormesis response of marine and freshwater luminescent bacteria to metal exposure
}

\author{
KAILI SHEN ${ }^{1,2}$, CHAOFENG SHEN ${ }^{1,2, *}$, YUAN LU $^{3}$, XIANJIN TANG ${ }^{1}$, CONGKAI $^{2}$ \\ ZHANG $^{2}$, XINCAI CHEN ${ }^{1,2}$, JIYAN SHI $^{1,2}$, QI LIN ${ }^{1,2}$, YINGXU CHEN $^{1,2}$ \\ ${ }^{1}$ Department of Environmental Engineering, Zhejiang University, Huajiachi Campus, 268 Kaixuan Road, \\ Hangzhou, Zhejiang 310029, China. \\ ${ }^{2}$ MOE Key Lab of Environmental Remediation and Ecosystem Health, College of Environmental \& Resources \\ Science, Zhejiang University, Hangzhou 310029, China. \\ ${ }^{3}$ Huzhou Vacational and Technical College, Huzhou Zhejiang 313000, China.
}

\begin{abstract}
The stimulatory effect of low concentrations of toxic chemicals on organismal metabolism, referred to as hormesis, has been found to be common in the widely used luminescence bioassay. This paper aims to study the hormesis phenomenon in both marine and freshwater luminescent bacteria, named Photobacterium phosphorem and Vibrio qinghaiensis. The effects of $\mathrm{Cu}$ (II), $\mathrm{Zn}$ (II), Cd (II) and $\mathrm{Cr}$ (VI) on luminescence of these two bacteria were studied for 0 to 75 minutes exposure by establishing dose- and time-response curves. A clear hormesis phenomenon was observed in all four testing metals at low concentrations under the condition of luminescence assays.
\end{abstract}

Key terms: Hormesis, bioluminescence, Q67, T3.

\section{INTRODUCTION}

Both analytic chemistry and bioassays are useful tools in assessing environmental risk of harmful substances. In recent years, a variety of biological models such as bacteria, microalgae, cultured cells and other organisms have been adapted to toxicological studies, with the result of making toxicity testing reliable, sensitive, cost-effective, and rapid (Fargašová, 1994; Ghosh et al., 1996; Radix et al., 2000). The standard Microtox bioassay, which measures the decrease in light emission by $V$. fischeri (strain NRRLB-11177) bacteria exposed to noxious chemicals, is one of the most widely used commercial tests in toxicity screening. This model has been successfully used to evaluate the toxicity of a large number of chemicals (Arufe et al., 2004; Fulladosa et al., 2007a). However, the narrow $\mathrm{pH}$ operating range (6.5-7.5) and the necessary salinity $(2-3 \% \mathrm{NaCl})$, have limited its actual use in environmental sample testing (Hinwood et al., 1987). Vibrio qinghaiensis is a species of freshwater luminescent bacterium, isolated from an edible fish (Zhu et al., 1994). This bacterium exhibits a wide $\mathrm{pH}$ tolerance and can be luminous in freshwater. It is a useful and promising tool in toxicity testing (Ma et al., 1999).

The stimulatory effect of low concentrations of toxic chemicals on organismal metabolism, referred to as hormesis, is common in luminescent bioassay (Fulladosa et al., 2005b; Fulladosa et al., 2007b). The aim of this study was to examine whether the hormesis response is ubiquitous in the testing of metals using freshwater bacterium Vibrio qinghaiensis (strain Q67) bioluminescence assay. Hormesis response was also examined with the marine bacterium, Photobacterium

\footnotetext{
* Corresponding Author: Chaofeng Shen, Department of Environmental Engineering, Zhejiang University, 268 Kaixuan Road, Hangzhou 310029, China; Telephone: +86-571-8603-6775; E-mail: ysxzt@zju.edu.cn
} 
phosphorem (strain T3), which is the strain recommended for luminescent bioassay by the Chinese Environmental Protection Agency (China-NEPA, 1995).

\section{METHODS}

The freshwater luminescent bacterium Q67 was kindly provided by Professor Zijian Wang and Dr. Mei Ma from Research Center for Eco-Environmental Sciences, Chinese Academy of Science. Lyophilized T3 bacterium was obtained commercially from Nanjing Institute of Soil Science, Chinese Academy of Science. The tested heavy metals, $\mathrm{Cr}$ as $\mathrm{K}_{2} \mathrm{Cr}_{2} \mathrm{O}_{7}, \mathrm{Zn}$ as $\mathrm{ZnSO}_{4}, \mathrm{Cu}$ as $\mathrm{CuSO}_{4}$ and $\mathrm{Cd}$ as $\mathrm{CdCl}_{2}$, were analytic grade. In order to avoid metal precipitation, stock solutions of each salt, obtained by dissolving the corresponding amount of salt in test medium, were adjusted to $\mathrm{pH} 5.4(\mathrm{Cr}$, $\mathrm{Zn}, \mathrm{Cd})$ and $4.5(\mathrm{Cu})$ respectively using 0.1 $\mathrm{N} \mathrm{NaOH}$ or $\mathrm{HCl}$ according to the testing protocol of luminometer.

The culture and assay methods are similar to those of Ma (Ma et al., 1999). Briefly, each bacterium was inoculated from a stock culture, which is maintained on culture medium agar at $4^{\circ} \mathrm{C}$, to a fresh agar and cultured at $22 \pm 1^{\circ} \mathrm{C}$ for $24 \mathrm{~h}$. The cells were further grown in liquid culture medium by shaking $(120 \mathrm{r} / \mathrm{min})$ at $22 \pm 1^{\circ} \mathrm{C}$ for $18 \mathrm{~h}$ and harvested by centrifuge at $3000 \mathrm{rpm}$ for $10 \mathrm{~min}$. The pellet was resuspended with test medium and centrifuge twice. Bacterial suspension was kept at $22 \pm 1^{\circ} \mathrm{C}$ for $30 \mathrm{~min}$ before the test. The assay was conducted in triplicates. Before each test, the light unit of suspension was adjusting to $300-900$ by adding test mediums. The assays of both Q67 and T3 were carried out by adding 0.1 $\mathrm{ml}$ bacterial suspension and $0.9 \mathrm{ml}$ test medium to a glass tube. It was thoroughly mixed and the initial light unit was recorded by Model Toxicity Analyzer DXY-2 (made by Nanjing Institute of Soil Science, Chinese Academy of Science) every $15 \mathrm{~min}$ incubation at $22 \pm 1{ }^{\circ} \mathrm{C}$.

\section{RESULTS}

The results are shown in Fig. 1-4. The figures describe an enhancement of light output above the controls for all the metals used in liquid culture bioassays at certain concentrations. Effects on luminescence, as studied by establishing dose- and timeresponse curves, confirmed that low doses of these poisonous metal ions were not
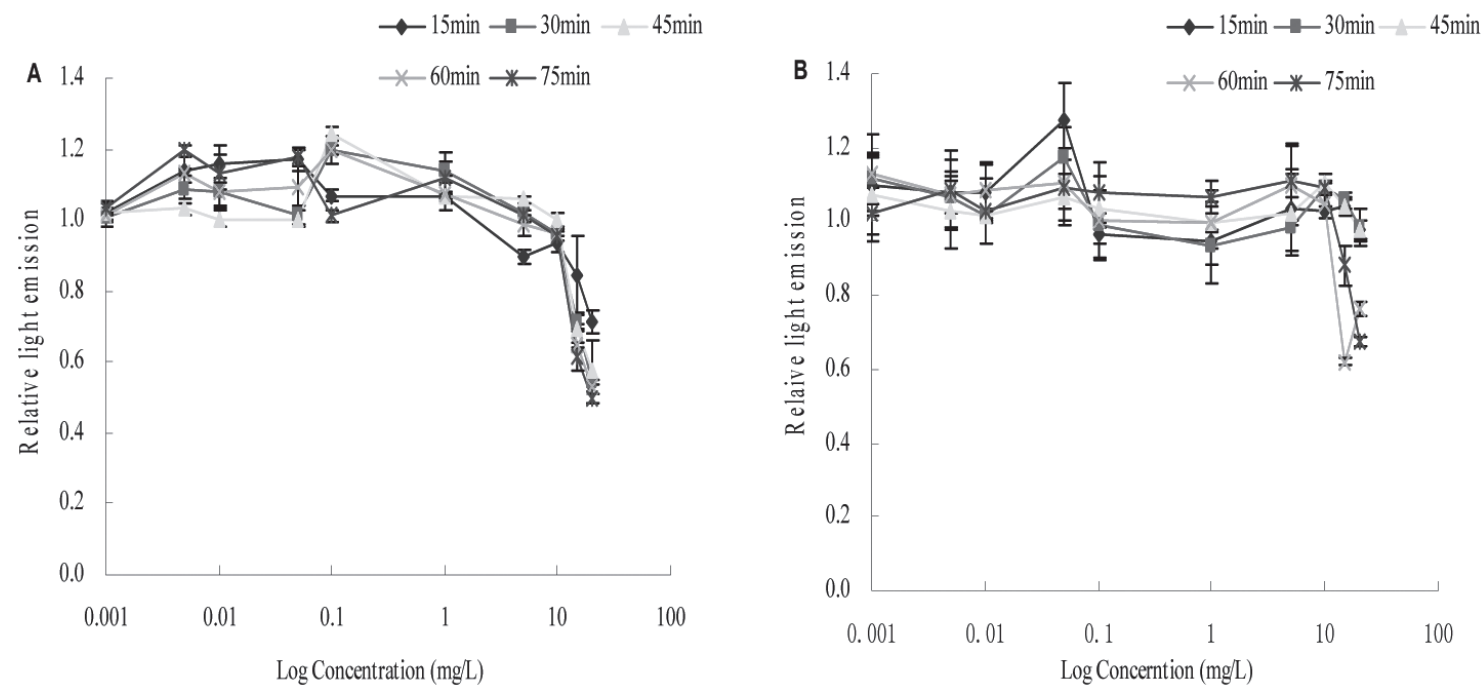

Figure 1: Dose-response curves for $\mathrm{Cu}$ (II). Decrease of light emission of (A) T3 and (B) Q67 from 15 to 75 minutes of exposure as a function of different metal concentration in the testing medium. Values are the mean of three replicates \pm SD. 
particularly toxic to either Q67 or T3. In contrast, it was possible to observe a clear hormesis phenomenon in each exposure.

Fig.1 shows the effect of different concentrations of $\mathrm{Cu}$ (II) in testing media on Q67 and T3 luminescence. In general, an undulant response was evident with limited enhancement in light output. As to $\mathrm{Zn}$ (II), the increase of luminescence was also found in the low concentration (especially those below to $1 \mathrm{mg} / \mathrm{L}$ ) within two bacteria (Fig. 2).

For Cd (II) exposure, both bacteria exhibited hormesis phenomenon (Fig. 3). However, their performances were different. With concentrations as high as 5 $\mathrm{mg} / \mathrm{L}$, inhibition on Q67 was already obvious, while even $10 \mathrm{mg} / \mathrm{L} \mathrm{Cd}$ (II) could cause T3 luminescence stimulation. This phenomenon indicated that $\mathrm{T} 3$ has stronger Cd (II) tolerance than Q67. The condition to $\mathrm{Cr}$ (VI) exposure is different from those of Cd (II) (Fig. 4). Although hormesis was observed as well, T3 exhibited higher sensitivity than Q67.

\section{DISCUSSION}

Low levels of copper did not greatly decrease bacteria luminescence, instead, those low concentrations were observed to increase luminescence intensity compared to the control. This phenomenon could be related to hormesis, which is defined as a stimulatory beneficial effect of very low concentrations of toxic chemicals on organisms (Calabrese, 1999a). Comparison between the two bacteria showed that Q67 was more sensitive than T3 to $\mathrm{Cu}$ (II) exposure. Luminescence stimulated by $\mathrm{Zn}$ (II) exposure has also been described by Christofi et al. (2002), who found an enhancement of luminescence induced by low concentrations of zinc. The toxicity of copper and zinc on bacteria might be explained by their bactericidal and antimicrobial nature, which might strongly affect bacterial enzymatic systems, as suggested by the reports related to $V$. fischeri (Fulladosa et al., 2005a).

Neither bacterium showed serious toxicity from $\mathrm{Cd}$ (II) and $\mathrm{Cr}$ (VI). It was reported that some Gram-negative bacteria, including the widely used Microtox luminescent bacterium $V$. fischeri, are not sensitive to cadmium exposure (Fulladosa et al., 2005a). The low toxicity of cadmium might result from the presence of exopolysaccharides on the outer layer of the bacteria membrane, which has been found to adsorb and trap cadmium. Since both
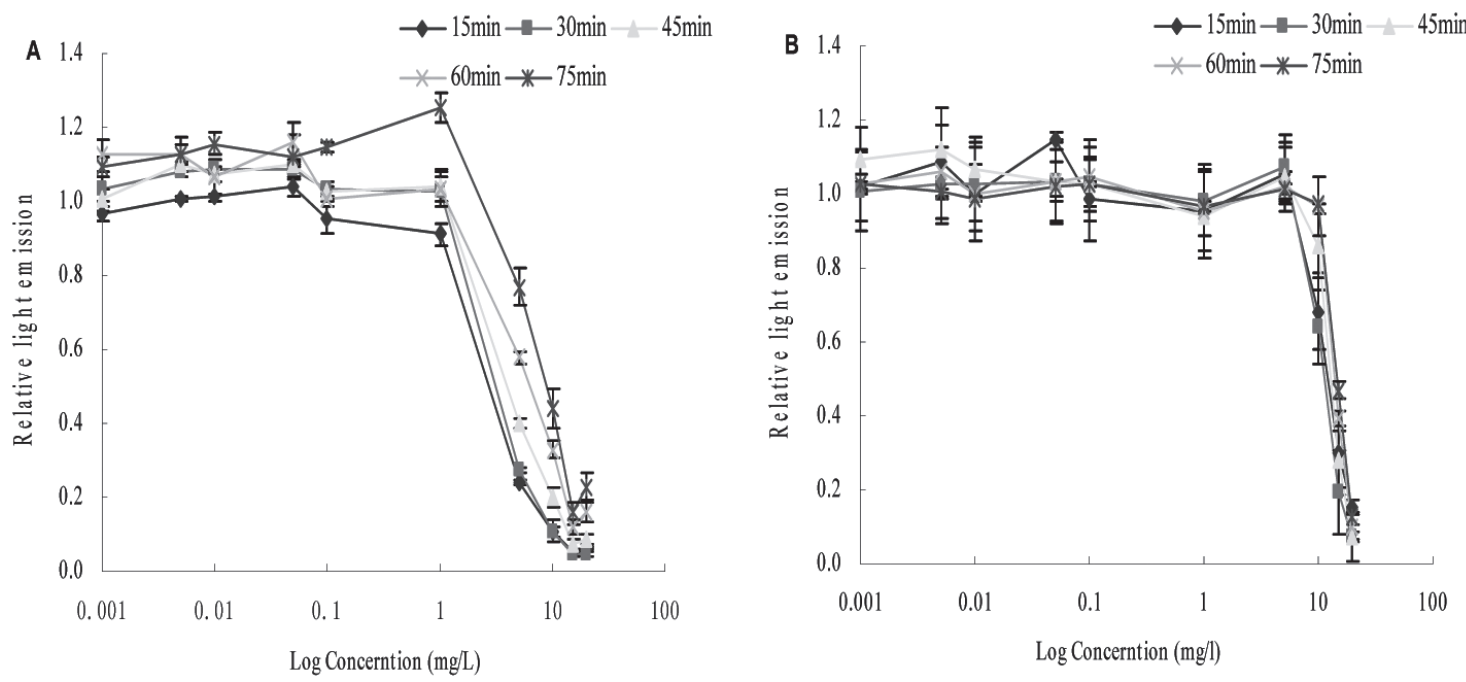

Figure 2: Dose-response curves for Zn (II). Decrease of light emission of (A) T3 and (B) Q67 from 15 to 75 minutes of exposure as a function of different metal concentration in the testing medium. Values are the mean of three replicates \pm SD. 
Q67 and T3 are Gram-negative bacteria, they may have the same cadmium tolerance mechanism. Gellert (2000) concluded the concerned factors causing toxicity differences in related elements. The cell wall composition which concerning the element uptake by bacteria was involved. Interactions between toxic elements and enzymes or allosteric effectors at critical steps of metabolic pathways related to supply cell energy might be one possible mechanism. Moreover, interactions of the toxic elements with the luciferase complex, which affects luminescence, might be another reason for the different toxicity levels.

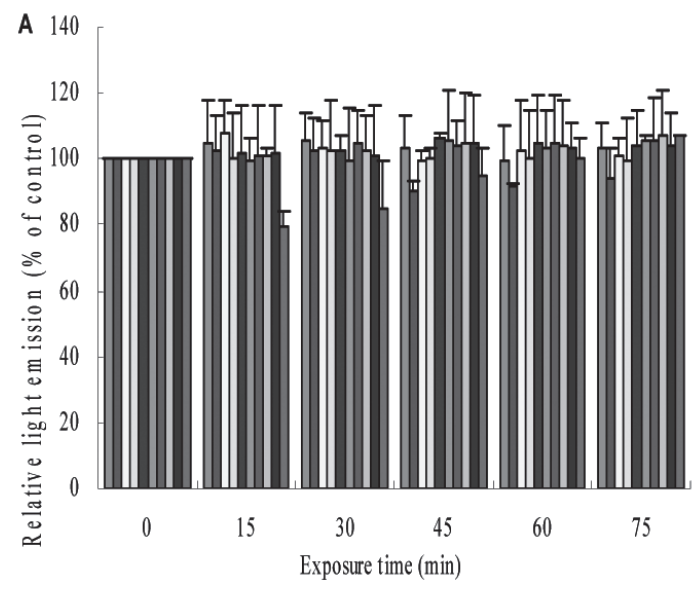

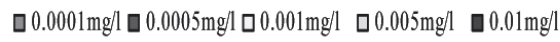

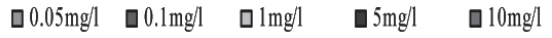

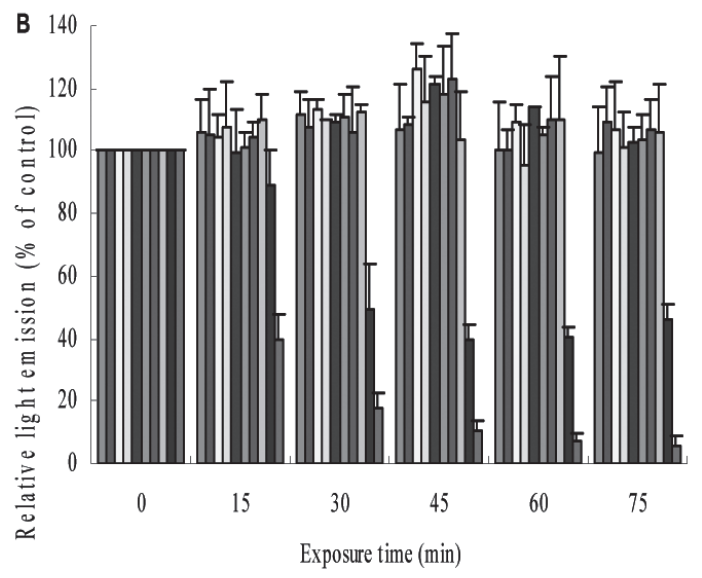

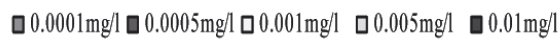

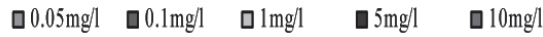

Figure 3: Toxicity of Cd (II) on (A) T3 and (B) Q67. Dose-response plot (light emission as a function of concentration). Bacteria were exposed to $\mathrm{Cd}$ (II) for up to 75 minutes. Values are the mean of three replicates \pm SD.

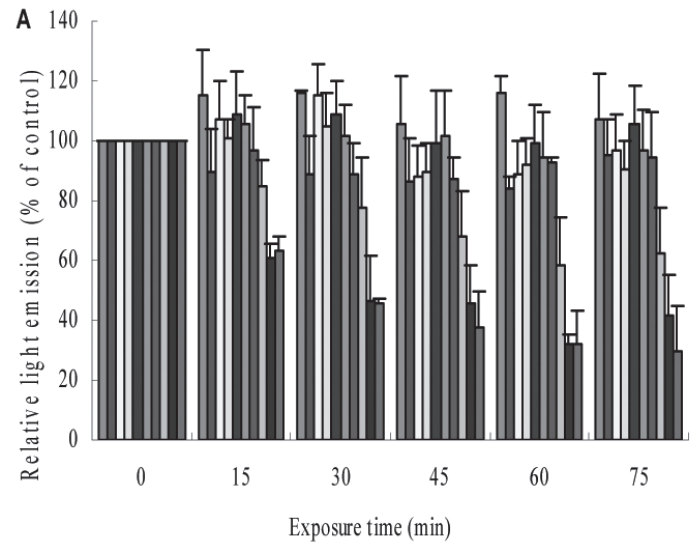

$\square 0.0001 \mathrm{mg} / \mathrm{l} \mathbf{0} 0.0005 \mathrm{mg} / \mathrm{l} \mathbf{0} 0.001 \mathrm{mg} / \mathrm{l} \quad \mathbf{0} 0.005 \mathrm{mg} / \mathrm{l} \quad \mathbf{0} 0.01 \mathrm{mg} / \mathrm{l}$

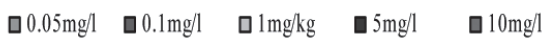

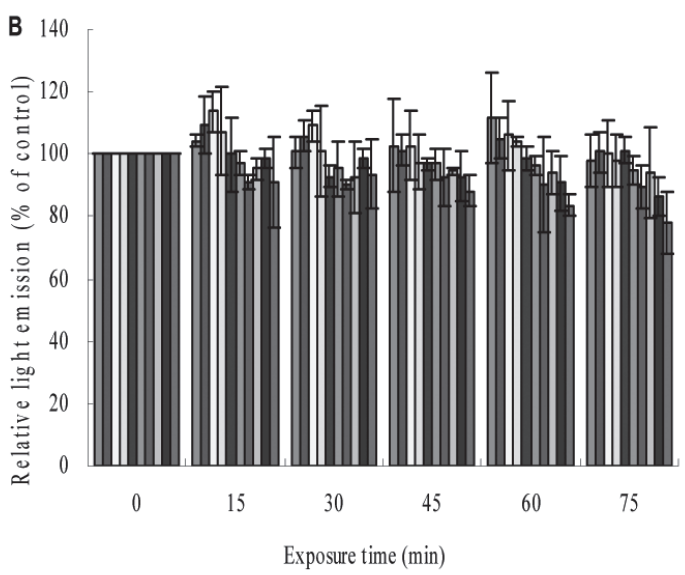

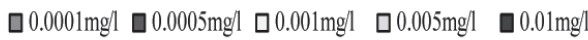

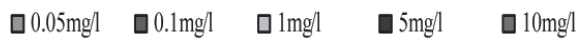

Figure 4: Toxicity of Cr (VI) on (A) T3 and (B) Q67. Dose-response plot (light emission as a function of concentration). Bacteria were exposed to $\mathrm{Cr}$ (VI) for up to75 minutes. Values are the mean of three replicates \pm SD. 
Fulladosa et al. (2005b) concluded that the mechanisms responsible for the low toxicity of $\mathrm{Cr}$ (VI) to bacteria may include the blockading of chromate transport, chromate-active efflux and the activation of the $\mathrm{Cr}$ (VI) decreasing mechanisms. The tolerance of bacteria to $\mathrm{Cr}$ (VI) has long been reported. A range of $\mathrm{Cr}$ (VI)-resistant bacteria have been proven able to reduce chromate into $\mathrm{Cr}$ (III). V. fischeri was also found to be able to decrease chromate actively. Our results about the poor toxicity of chromate in Q67 might be partly attributed to this mechanism.

Hormesis is a widespread phenomenon in the exposure to metals with luminescent bacteria. But hormesis is rarely mentioned and accepted in mainstream toxicology. One reason that hormesis is not often reported in bioassays, as well as luminescent bacteria, is probably the subacute concentrations used (Calabrese et al., 1999b). Furthermore, the hormesis response is always very minor and is often considered as an experimental error or distortion of results. The data showing the elevated response (increase in bioluminescence in a test culture) is ignored in toxicity calculations. Additionally, experimental design has an effect on the observation of hormesis (Teeguarden et al., 1998), as when the concentrations of toxin being tested are too broadly spread, thus missing the response.

\section{ACKNOWLEDGEMENTS}

This work was supported by the Program for Changjiang Scholars and Innovative Research University Teams (IRT0536).

\section{REFERENCES}

ARUFE MJ, ARELLANO J, MORENO MJ, SARASQUETE C (2004) Toxicity of a commercial herbicide containing terbutryn and triasulfuron to seabream (Sparus aurata L.) larvae: a comparison with the Microtox test. Ecotoxicol Environ Saf 59: 209-216
CALABRESE EJ (1999a) Evidence that hormesis represents an overcompensation response to a disruption in homeostasis. Ecotoxicol Environ Saf 42: 135-137

CALABRESE EJ, BALDWIN LA, HOLLAND CD (1999b) Hormesis: A highly generalizable and reproducible phenomenon with important implications for risk assessment. Risk Anal 19: 261-281

CHINA-NEPA (1995) Water quality-determination of the acute toxicity-luminescent bacteria test. GB/T 154411995

CHRISTOFI N, HOFFMANN C, TOSH L (2002) Hormesis responses of free and immobilized light-emitting bacteria. Ecotoxicol Environ Saf 52: 227-231

FARGAŠOVÁ A (1994) Comparative toxicity of five metals on various biological subjects. Bull Environ Contam Toxicol 53: 317-324

FULLADOSA E, MURAT JC, BOLLINGER JC, VILLAESCUSA I (2007a) Adverse effects of organic arsenical compounds towards Vibrio fischeri bacteria. Sci Total Environ 377: 207-213

FULLADOSA E, MURAT JC, MARTINEZ M, VILLAESCUSA I (2005a) Patterns of metals and arsenic poisoning in Vibrio fischeri bacteria. Chemosphere 60: 43-48

FULLADOSA E, MURAT JC, VILLAESCUSA I (2005b) Effect of Cadmium (II), Chromium (VI) and Arsenic (V) on long-term viability- and growth- inhibition assays using Vibrio fischeri marine bacteria. Arch Environ Contam Toxicol 49: 299-306

FULLADOSA E, VILLAESCUSA I, BOLLINGER JC, MURAT JC (2007b) Effect of arsenic compounds on Vibrio fischeri light emission and butyrylcholinesterase activety. Environ Chem Lett 5: 115-119

GELLERT G (2000) Sensitivity and significance of luminescent bacteria in chronic toxicity testing based on growth and bioluminescence. Ecotoxicol Environ Saf 45: 87-91

GHOSH SK, DOCTOR PB, KULKARNI PK (1996) Toxicity of zinc in three microbial test systems. Environ Toxic Water 11: 13-19

HINWOOD AL, MCCORMICK MJ (1987) The effect of ionic solutes on EC50 values measured using the Microtox test. Toxic Assess 2: 449-461

MA M, TONG Z, WANG Z, ZHU W (1999) Acute toxicity bioassay using the freshwater luminescent bacterium Vibrio-qinghaiensis sp. Nov.-Q67. Bull Environ Contam Toxicol 62: 247-253

RADIX P, LÉONARD M, PAPANTONIOU C, ROMAN G, SAOUTER E, GALLOTTI-SCHMITT S, THIÉBAUD H, VASSEUR P (2000) Comparison of four chronic toxicity tests using algae, bacteria, and invertebrates assessed with sixteen chemicals. Ecotoxicol Environ Saf 47: 186-194

TEEGUARDEN JG, DRAGAN YP, PITOT HC (1998) Implications of hormesis on the bioassay and hazard assessment of chemical carcinogens. Human Exp Toxicol 17: 254-258

ZHU WJ, WANG J, CHEN XY, ZHAXI CR, YANG Y, SONG Y (1994) A new species of luminous bacteria Vibrio qinghaiensis sp. NOV. Oceanologia et Limnologia Sinica 25: 273-279 (Chinese article). 
